\title{
THE BINDER INDEX - A PARAMETER THAT INFLUENCES THE STRENGTH OF GEOPOLYMER CONCRETE
}

Rama SESHU D. ${ }^{*}$, SHANKARAIAH R. ${ }^{2}$, Sesha SRINIVAS B. ${ }^{3}$

\begin{abstract}
Geopolymer concrete (GPC) is an environmentally friendly material in the sense that it uses industrial by-products such as ground granulated blast furnace slag (GGBS) and fly ash (FA), which are activated by an alkaline solution. This paper presents an experimental investigation concerning the strength of the GPC and its relation to a new parameter called the 'Binder Index (BI)'. The parameters considered in the investigation include GGBS to fly ash ratios $(0.250 .43,0.67,1.0,1.5$, and 2.3$)$ and the molarity of the alkaline activator $(6,8,10$, and 12). The binder index combines the effect of the GGBS to the fly ash ratio and the molarity of the alkaline activator. The results have shown that the strength of the GPC is significantly influenced by varying the binder index. The results indicate that a nonlinear relation exists between the binder index and the compressive strength of the GPC and the binder index and the modulus of rupture.
\end{abstract}

\author{
Address \\ 1 National Institute of Technology, Warangal, India \\ 2 Housing Board, and Research Scholar, Kakatiya Univ., Warangal, \\ India \\ 3 University College of Engineering, Kothagudem, Kakatiya Univ., \\ India
}

* Corresponding author: ramadrs@gmail.com

\section{Key words}

- Geopolymer,

- Concrete,

- Strength,

- GGBS,

- Fly ash,

- Binder index.

\section{INTRODUCTION}

The use of alkali-activated binders in the development of concrete is acquiring significance from the point of view of sustainability. Such concrete is known as geopolymer concrete (GPC). The increased awareness of the environmental effects of the cement industry has given scope for the development of alternative concrete materials (Davidovits, 1994; Wang et al., 1995; Joshi, 2014). In this context the development of geopolymer concrete is being viewed as an emerging class of concrete material and could be the next generation of concrete for applications in the civil engineering infrastructure. The commonly used combination of the alkaline activator is $\mathrm{NaOH}$ and a $\mathrm{Na}_{2} \mathrm{SiO}_{3}$ solution. These rich in silica by-products form a binder matrix with the alkaline solution to the bound aggregate and produce hardened concrete.

Various researchers (Anuradha et al., 2012; Ashley Russell Kotwal et al., 2015; Davidovits, 1994) have proposed the use of waste material such as fly ash and ground granulated blast furnace slag along with a high alkaline solution as activators in the development of GPC. The curing conditions and temperature significantly impact the polymerization process in GPC (Hardjito et al., 2004; Lloyd N., Rangan V., 2009; Rangan B.V., 2008). Also, it was concluded that a combination of sodium hydroxide and sodium silicate solutions can be a good application for activators, and a higher concentration of the sodium hydroxide solution and a curing temperature can enable the concrete compressive strength to be higher (Rama Seshu et al., 2017). Various authors have studied the importance of the molar ratio of $\mathrm{Na}_{2} \mathrm{SiO}_{3} / \mathrm{NaOH}$ and suggested 2.5 for the maximum compressive strength for a constant binder content. More further, a mix design of GPC has been proposed (Rangan B.V., 2008; Rajamane N. P., Jeyalakshmi R., 2014) for fly ash-based geopolymer concrete considering different mix proportions, and a mix design has been developed by varying the water to geopolymer solid ratio with two different molarities of $\mathrm{NaOH}$, i.e., $8 \mathrm{M}$ and $12 \mathrm{M}$.

In view of the past work done on GPC, the present investigation is aimed at studying the combined effect of GGBS, FA, and the molarity of the alkaline activator on the compressive strength and modulus of 
rupture of GPC. A unified parameter known as the 'Binder Index (BI)' is introduced to quantify the effects of the GGBS to FA ratio and the molarity of the alkaline activator on the strength of the GPC. With the use of GGBS and fly ash, the geopolymer concrete that is produced can be called 'Binary blended GPC'.

\section{EXPERIMENTAL PROGRAM}

The experimental program consisted of finding the compressive strength and modulus of rupture (tensile strength in bending) of GGBS and FA-based geopolymer concrete by casting and testing cubes sized $150 \mathrm{~mm} \times 150 \mathrm{~mm} \times 150 \mathrm{~mm}$ and prisms sized $100 \mathrm{~mm} \times$ $100 \mathrm{~mm} \times 400 \mathrm{~mm}$.

\subsection{Materials used}

Fly ash and GGBS are used as binders in this research work. The GGBS was obtained from Toshali Cements Pvt. Ltd., Bayyavaram, India, and fly ash from the National Thermal Power Plant, Ramagundam, India. The specific gravity of the GGBS and fly ash are 2.90 and 2.17 respectively. Details of the chemical composition are shown in Table 1.

Tab. 1 Chemical composition of fly ash and GGBS (\% by mass)

\begin{tabular}{|c|c|c|c|c|c|c|c|c|}
\hline & $\mathrm{SiO}_{2}$ & $\mathrm{Al}_{2} \mathrm{O}_{3}$ & $\mathrm{Fe}_{2} \mathbf{O}_{3}$ & $\mathrm{SO}_{3}$ & $\mathbf{C a O}$ & $\mathbf{M g O}$ & $\mathrm{Na}_{2} \mathrm{O}$ & $\mathbf{L O I}$ \\
\hline Fly ash & 60.12 & 26.63 & 4.22 & 0.32 & 4.10 & 1.21 & 0.20 & 0.85 \\
\hline GGBS & 34.16 & 20.10 & 0.81 & 0.88 & 32.8 & 7.69 & -- & -- \\
\hline
\end{tabular}

Fine Aggregate: Robo sand (RS), which is also known as manufactured sand and is made out of crushed stone, was used as a fine aggregate instead of normal river sand. The RS used conformed to Zone 2 according to IS: 383 , and its specific gravity and bulk density are 2.65 and 1.45 gram/c.c. respectively.

Coarse Aggregate: Crushed granite of a $20 \mathrm{~mm}$ nominal size, which was obtained from a local crushing unit, was used as the coarse aggregate; the aggregate is well-graded according to IS:383. The specific gravity and bulk density are 2.80 and $1.5 \mathrm{~g} / \mathrm{cm}^{3}$.

Water: Potable water was used in the experimental work for the preparation of the alkaline solution.

Alkaline Solution: The molarity of the sodium hydroxide solution used varied from $6 \mathrm{M}$ to $12 \mathrm{M}$. The sodium hydroxide pellets used in preparing the $\mathrm{NaOH}$ solution is given in Table 2. The sodium silicate solution with a chemical composition of $\mathrm{NaO}-8 \%$, $\mathrm{Sio}_{2}-28 \%$ and
$\mathrm{H}_{2} \mathrm{O}-64 \%$ by mass was used. The ratio of the sodium silicate solution to the sodium hydroxide solution was 2.5 , and the mixed solution was stored for 24 hours at room temperature $\left(25 \pm 2^{\circ} \mathrm{C}\right)$ and a relative humidity of $65 \%$ before it was used for casting.

Tab. 2 Materials used in preparing $\mathrm{NaOH}$ solution

\begin{tabular}{|c|c|c|c|c|}
\hline & $6 \mathrm{M}$ & $8 \mathrm{M}$ & $10 \mathrm{M}$ & $12 \mathrm{M}$ \\
\hline Sodium Hydroxide Pellets $(\mathrm{g})$ & 200 & 255 & 306 & 354 \\
\hline Water $(\mathrm{g})$ & 800 & 745 & 694 & 646 \\
\hline
\end{tabular}

\subsection{Mix Proportions:}

After an investigation of the various mixes and testing the cast specimens, the final mix proportions shown in Table 3 were adopted to carry out the preparation of the concrete and determine its properties.

\subsection{Casting of the GPC Specimens}

The dry materials were mixed using a rotating $100 \mathrm{~kg}$ capacity drum type pan mixer and an alkaline liquid and super plasticizer (SP 430, Make: Fosroc Chemicals) at the optimum dosage were added. Proper homogenous mixing was obtained by continuous mixing for about 5 minutes. The fresh mixes that were prepared were cohesive and segregation resistant. Immediately after the mixing, the fresh GPC was placed in the stipulated number of cube and prism moulds, which was followed by compacting it on a jolting table. After compaction, the top surface of the moulds was leveled with a trowel.

The specimens were de-moulded after 24 hours of casting and cured outdoors, i.e., the specimens were left outside to be air dried for a period of 28 days. The room temperature and relative humidity measured were $35 \pm 2{ }^{\circ} \mathrm{C}$ and $75 \%$ respectively.

For determining the compressive strength of the GPC, a total of 144 cubes representing 6 different GGBS/FA ratios $(0.25,0.43,0.67$, $1.0,1.5$ and 2.3), 4 different molarities $(6,8,10$, and 12) of the alkaline solution, two different curing periods ( 7 and 28 days), and three identical specimens for each variation, were cast and tested. Similarly for determining the modulus of rupture of the GPC, a total of 72 prism specimens representing 6 different GGBS/FA ratios $(0.25,0.43,0.67$, $1.0,1.5$, and 2.3), 4 different molarities $(6,8,10$, and 12) of the alkaline solution, and three identical specimens for each variation, were cast and tested at the end of 28 days of curing outside in ambient temperatures.

Tab. 3 Materials used in GPC *

\begin{tabular}{|c|c|c|c|c|c|c|c|c|}
\hline \multirow{2}{*}{ SNo } & & & \multicolumn{5}{|c|}{ Materials (Kg ) } \\
\cline { 2 - 10 } & FA: GGBS & GGBS/FA ratio & Coarse Agg. & Robo Sand & Fly Ash & GGBS & NAOH Solution & Sodium Silicate \\
\hline 1 & $80: 20$ & 0.25 & 18.00 & 13.20 & 7.85 & 2.00 & 1.80 & 4.50 \\
\hline 2 & $70: 30$ & 0.43 & 18.00 & 13.20 & 6.90 & 2.95 & 1.80 & 4.50 \\
\hline 3 & $60: 40$ & 0.67 & 18.00 & 13.20 & 5.91 & 3.94 & 1.80 & 4.50 \\
\hline 4 & $50: 50$ & 1.00 & 18.00 & 13.20 & 4.93 & 4.92 & 1.80 & 4.50 \\
\hline 5 & $40: 60$ & 1.50 & 18.00 & 13.20 & 3.94 & 5.91 & 1.80 & 4.50 \\
\hline 6 & $30: 70$ & 2.30 & 18.00 & 13.20 & 2.95 & 6.90 & 1.80 & 4.50 \\
\hline
\end{tabular}

*for casting 6 cubes for each variation 


\section{TESTING OF GPC}

\subsection{Compressive Strength of GPC}

The cube specimens were tested on a compression testing machine with a capacity of $2000 \mathrm{kN}$. The load applied was continuously increased at a constant rate until the resistance of the specimen to the increasing load broke down and could no longer be sustained. The maximum load applied to the specimen was recorded. The testing was done according to IS 516 (1999). The testing of the specimens was carried out at the end of 7 days (7D) and 28 days (28D) of curing outdoors. The compression strength of the GPC for the different GGBS to the fly ash ratio and for different molarities of the alkaline activator is given in Table 4 .

\subsection{Modulus of Rupture (Tensile Strength in Bending) of GPC}

The prism specimens were tested under standard four points bending according to IS 516 (1999). A four-point flexure test fixture arrangement attached to a universal testing machine with a capacity of $200 \mathrm{kN}$ was used. The load applied was increased continuously at a constant rate until the resistance of the specimen to the increasing load broke down and could no longer be sustained. The maximum load applied to the specimen was recorded. The testing of the specimens was carried out at the end of 28 days (28D) of ambient curing oudoors. The modulus of rupture of the GPC for the different GGBS to the fly ash ratio and for the different molarities of the alkaline activator is given in Table 5 .

\section{RESULTS AND DISCUSSION}

\subsection{Effect of GGBS to fly ash ratio}

\subsubsection{On the Compressive Strength of the GPC}

The effect of the GGBS to the fly ash ratio on the compressive strength of the GPC (at the end of 7 days and 28 days of ambient curing) for a particular molarity of the alkaline activator is shown in Figs.1.1 to 1.4. From these figures it can be observed that the compression strength of the GPC increased with an increase in the GGBS to FA ratio. However, the rate of increase of the compressive strength is higher for the GGBS to FA ratios lower than 1.0 as is shown by the percent increase of strength values with the changes in molarities presented in Table 4.

\subsubsection{On the Modulus of Rupture of the GPC}

The effect of the GGBS to fly ash ratio on the modulus of rupture of the GPC for the different molarities of the alkaline activator is shown in Fig.3. From these figures it can be observed that the modulus of rupture of the GPC increased with an increase in the GGBS to FA ratio. However, the rate of increase of the modulus of rupture is slightly higher for the GGBS to FA ratios lower than 1.0 as is shown by the percent increase of strength values with the changes in molarity presented in Table 5.

\subsection{Effect of the molarity of the alkaline activator}

\subsubsection{On the compressive strength of the GPC}

The effect of the molarity of the alkaline activator for the different GGBS to FA ratios on the 28-day compressive strength of the GPC is shown in Fig.2. In general, as the molarity increased, the 28day compressive strength of the GPC also increased. However, the increase in strength is not in proportion to the increase in molarity. As the GGBS to FA ratio increased from 0.25 to 2.3 , the 28-day compressive strength of the GPC increased by $175 \%, 156 \%, 139 \%$ and $107 \%$ for the molarity of the alkaline activator of $6 \mathrm{M}, 8 \mathrm{M}, 10 \mathrm{M}$, and $12 \mathrm{M}$ respectively.

\subsubsection{On the Modulus of Rupture of the GPC}

The effect of the molarity of the alkaline activator for the different GGBS to FA ratios on the 28-day modulus of the rupture of GPC is shown in Fig. 3. In general, as the molarity increased, the 28-day modulus of the rupture of GPC also increased. However, the increase in strength is not in proportion to the increase in molarity. As the GGBS to FA ratio increased from 0.25 to 2.3 , the 28 -day modulus of the rupture of the GPC increased by $89.8 \%, 96.1 \%, 77.6 \%$, and $73.6 \%$ for the molarity of the alkaline activator of $6 \mathrm{M}, 8 \mathrm{M}, 10 \mathrm{M}$, and $12 \mathrm{M}$ respectively.

\subsection{Relation between the 7-day and 28-day compressive strength of the GPC}

The relation between the 7-day (7D) and 28-day (28D) compressive strength of the GPC is shown in Fig. 4. A non-linear variation was observed between the 7D and 28D compressive strength of the GPC. The following non-linear equation can be used to relate the 7D to the $28 \mathrm{D}$ strength ratio of the GPC. The correlation coefficient of the equation is 0.53 .

$$
\begin{gathered}
\mathrm{f} 28=3.137(\mathrm{f} 7)^{0.729} \\
\mathrm{R}^{2}=0.942
\end{gathered}
$$

\subsection{Relation between the modulus of rupture and the compressive strength of the GPC}

The relation between the modulus of rupture ( $\mathrm{ft}$ ) and the 28-day compressive strength (f28) of the GPC is shown in Fig. 5. A non-linear variation was observed between the modulus of rupture and the compressive strength of the GPC. The following non-linear equation can be used to relate the modulus of rupture and the compressive strength of the GPC.

$$
\begin{aligned}
\mathrm{ft}= & 0.334(\mathrm{f} 28)^{0.591} \\
& \mathrm{R}^{2}=0.926
\end{aligned}
$$

The above relation can be rewritten approximately as

$$
\mathrm{ft}=0.467 \sqrt{ }(\mathrm{f} 28)
$$

The correlation coefficient of the equation is 0.964 . 


\section{EFFECT OF THE BINDER INDEX}

To study the combined effect of the GGBS to the fly ash ratio and the molarity of the alkaline activator, the 'Binder Index (BI)', a new parameter, has been used. The Binder Index is taken as the product of the GGBS to the fly ash ratio (GGBS/FA) and the molar concentration $(\mathrm{M})$ of the activator solution.

$$
\mathrm{BI}=(\mathrm{GGBS} / \mathrm{FA}) \times \mathrm{M}
$$

\subsection{Effect of the Binder Index on the Compressive Strength of the GPC}

The values of the compressive strength of the GPC at 7 days (f7) and 28 days (f28) of air curing (outdoor curing) with the level of the binder index (BI) are given in Table 6, and a variation of the same is shown in Fig. 6. This variation indicates that both the 7 and 28-day compressive strength of the GPC increased with an increase in the binder index. However, the increase in strength is not in proportion to

Tab. 6 Strength of GPC and Binder index

\begin{tabular}{|c|c|c|c|}
\hline \multirow{2}{*}{$\begin{array}{c}\text { Binder } \\
\text { Index } \\
\text { (Bi) }\end{array}$} & \multicolumn{2}{|c|}{ Compressive Strength of GPC (MPa) } & \multirow{2}{*}{$\begin{array}{c}\text { Modulus of } \\
\text { Rupture } \\
\text { of GPC (ft) } \\
\text { (MPa) }\end{array}$} \\
\hline & $\begin{array}{l}7 \text { days Strength } \\
\text { (f7) (Mpa) }\end{array}$ & $\begin{array}{l}28 \text { days Strength } \\
\text { (f28) (Mpa) }\end{array}$ & \\
\hline 1.5 & 12.23 & 16.62 & 1.77 \\
\hline 2.58 & 13.05 & 18.14 & 2.1 \\
\hline 4.02 & 21.3 & 24.97 & 2.475 \\
\hline 6 & 29.87 & 37.82 & 2.7 \\
\hline 9 & 35.58 & 41.69 & 3 \\
\hline 13.8 & 42.92 & 45.67 & 3.36 \\
\hline 2 & 12.64 & 19.27 & 1.83 \\
\hline 3.44 & 13.66 & 23.45 & 2.19 \\
\hline 5.36 & 22.43 & 30.17 & 2.55 \\
\hline 8 & 29.97 & 38.53 & 2.925 \\
\hline 12 & 37.72 & 42.71 & 3.09 \\
\hline 18.4 & 46.99 & 49.34 & 3.585 \\
\hline 2.5 & 14.07 & 22.53 & 2.055 \\
\hline 4.3 & 15.09 & 25.99 & 2.295 \\
\hline 6.7 & 24.16 & 37.41 & 2.61 \\
\hline 10 & 30.28 & 39.55 & 2.985 \\
\hline 15 & 40.37 & 43.83 & 3.12 \\
\hline 23 & 49.75 & 53.92 & 3.66 \\
\hline 3 & 19.47 & 27.93 & 2.16 \\
\hline 5.16 & 22.73 & 30.07 & 2.355 \\
\hline 8.04 & 27.01 & 39.65 & 2.64 \\
\hline 12 & 30.78 & 41.08 & 3.045 \\
\hline 18 & 40.98 & 44.75 & 3.36 \\
\hline 27.6 & 51.48 & 58 & 3.75 \\
\hline
\end{tabular}

the increase in the binder index. A non-linear variation exists between the binder index and the compressive strength of the GPC. The following best fit equations give the relation between the compressive strength of the GPC at 7 days and 28 days of air curing with the binder index (BI) along with the correlation coefficient $\left(\mathrm{R}^{2}\right)$. These relations holds good for a BI greater than 1.0.

$$
\begin{gathered}
\mathrm{f} 7=8.748(\mathrm{Bi})^{0.56} \\
\mathrm{R}^{2}=0.929 \\
\mathrm{f} 28=14.86(\mathrm{Bi})^{0.422} \\
\mathrm{R}^{2}=0.936
\end{gathered}
$$

\subsection{Effect of the Binder Index on the Modulus of Rupture} of the GPC

The values of the modulus of rupture of GPC at 28 days (ft) of curing oudoors at an ambient temperature with the level of the Binder Index (BI) are given in Table 6, and a variation of the same is shown in Fig. 7. This variation indicates that the modulus of rupture of the GPC at 28 days (ft) increased with an increase in the binder index. However, the increase in the modulus of rupture of the GPC is not in proportion to the increase in the binder index. A non-linear variation exists between the binder index and the modulus of rupture of the GPC. The following best fit equations give the relation between the modulus of rupture of the GPC with the binder index (BI) along with the correlation coefficient $\left(\mathrm{R}^{2}\right)$. These relations hold good for a BI greater than 1.0.

$$
\begin{gathered}
\mathrm{ft}=1.603(\mathrm{Bi})^{0.264} \\
\mathrm{R}^{2}=0.973
\end{gathered}
$$

From the above observations it can be concluded that the GGBS and FA combinations can be used to produce geopolymer concrete without the need for heat curing. The GGBS, which normally contains a substantial amount of calcium compared to that of fly ash, imparts the heat of hydration required for the polymerization process. Further, the new parameter 'Binder Index (BI)' significantly affects the strength of the GPC.

\section{CONCLUSIONS}

The following conclusions can be made from the experimental investigation presented.

1. The compressive strength and modulus of rupture of the GPC increased with the increase in the GGBS to FA ratio for the particular molarity of activator used, and the rate of increase of the compressive strength and modulus of rupture is more for the GGBS to FA ratio of less than 1.0.

2. The increase in compressive strength and modulus of rupture is not in proportion to the increase in molarity.

3. The new parameter called the 'binder index', which combines the effects of both GGBS to the fly ash ratio and the molar concentration of the activator solution, can be used to control the compressive strength and modulus of rupture of geopolymer concrete.

4. The relation between the binder index and compressive strength of the GPC and binder index and the modulus of rupture is non-linear.

5. A non-linear relation exist between the 7 and 28-day compressive strength of the GPC.

6. The fly ash and GGBS combination can be used to produce the GPC without the need for heat curing. 
Tab. 4 The compression strength of the GPC (MPa)

\begin{tabular}{|c|c|c|c|c|c|c|c|c|c|c|c|c|c|c|c|}
\hline \multirow{3}{*}{ SNo } & \multirow{3}{*}{$\begin{array}{c}\text { GGBS/ } \\
\text { FA }\end{array}$} & \multicolumn{12}{|c|}{ Molarity of Alkaline Activator } & \multirow{2}{*}{\multicolumn{2}{|c|}{$\begin{array}{l}\% \text { increase in } \\
\text { compressive } \\
\text { strength } \\
\text { as molarity } \\
\text { changes from } \\
6 \text { to } 12\end{array}$}} \\
\hline & & \multicolumn{3}{|c|}{$6 M$} & \multicolumn{3}{|c|}{$8 \mathbf{M}$} & \multicolumn{3}{|c|}{$10 \mathrm{M}$} & \multicolumn{3}{|c|}{$12 M$} & & \\
\hline & & 7D & 28D & 7D/28D & 7D & 28D & 7D/28D & 7D & 28D & 7D/28D & 7D & 28D & 7D/28D & $7 \mathrm{D}$ & $28 \mathrm{D}$ \\
\hline 1 & 0.25 & 12.23 & 16.62 & 0.736 & 12.64 & 19.27 & 0.656 & 14.07 & 22.53 & 0.624 & 19.47 & 27.93 & 0.697 & 59 & 68 \\
\hline 2 & 0.43 & 13.05 & 18.14 & 0.719 & 13.66 & 23.45 & 0.583 & 15.09 & 25.99 & 0.58 & 22.73 & 30.07 & 0.756 & 74 & 66 \\
\hline 3 & 0.67 & 21.3 & 24.97 & 0.853 & 22.43 & 30.17 & 0.743 & 24.16 & 37.41 & 0.646 & 27.01 & 39.65 & 0.681 & 27 & 59 \\
\hline 4 & 1 & 29.87 & 37.82 & 0.79 & 29.97 & 38.53 & 0.778 & 30.28 & 39.55 & 0.765 & 30.78 & 41.08 & 0.749 & 3.1 & 8.6 \\
\hline 5 & 1.5 & 35.58 & 41.69 & 0.853 & 37.72 & 42.71 & 0.883 & 40.37 & 43.83 & 0.921 & 40.98 & 44.75 & 0.916 & 15 & 7.3 \\
\hline 6 & 2.3 & 42.92 & 45.67 & 0.94 & 46.99 & 49.34 & 0.952 & 49.75 & 53.92 & 0.922 & 51.48 & 58 & 0.888 & 20 & 27 \\
\hline \multicolumn{2}{|c|}{$\begin{array}{l}\% \text { increase in } \\
\text { strength as } \\
\text { GGBS/FA in- } \\
\text { creases from } \\
0.25 \text { to } 2.30\end{array}$} & 251 & 175 & -- & 272 & 156 & -- & 253 & 139 & -- & 164 & 107 & -- & & \\
\hline
\end{tabular}

Tab. 5 The Modulus of Rupture of GPC (MPa) *

\begin{tabular}{|c|c|c|c|c|c|c|}
\hline \multirow{2}{*}{ SNo } & \multirow{2}{*}{ GGBS/FA } & \multicolumn{3}{|c|}{ Molarity of Alkaline Activator } & \multirow{2}{*}{$\begin{array}{c}\text { \% increase in Modulus of Rupture } \\
\text { as molarity changes from 6 to } 12\end{array}$} \\
\cline { 3 - 7 } & & $\mathbf{6 M}$ & $\mathbf{8 M}$ & $\mathbf{1 0 M}$ & $\mathbf{1 2 M}$ & 22.00 \\
\hline 1. & 0.25 & 1.77 & 1.83 & 2.06 & 2.16 & 12.38 \\
\hline 2. & 0.67 & 2.10 & 2.19 & 2.29 & 2.36 & 6.45 \\
\hline 3. & 1.00 & 2.48 & 2.55 & 2.61 & 2.64 & 12.96 \\
\hline 4. & 1.50 & 2.70 & 2.93 & 2.99 & 3.05 & 12.0 \\
\hline 5. & 2.30 & 3.00 & 3.09 & 3.12 & 3.36 & 10.11 \\
\hline 6. & 3.36 & 3.59 & 3.66 & 3.75 & 73.6 & \\
\hline \multicolumn{2}{r|}{$\%$} \\
\hline
\end{tabular}

*Modulus of Rupture of the GPC measured at 28 days of air curing

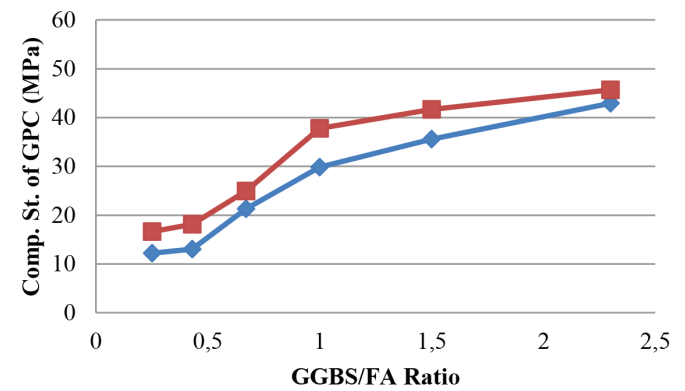

Fig. 1.1 Compressive Strength of the GPC vs GGBS/FA Ratio- 6 Molarity

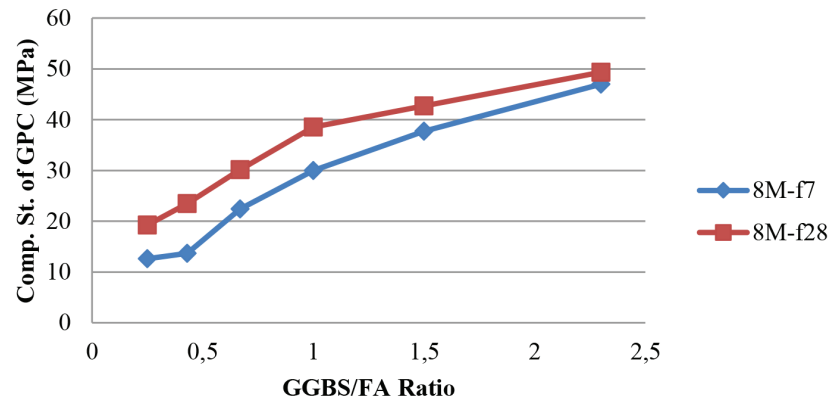

Fig. 1.2 Compressive Strength of the GPC vs GGBS/FA Ratio- 8 Molarity 


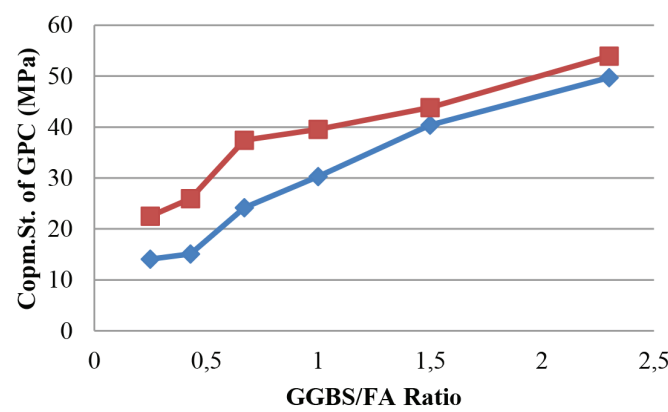

Fig. 1.3 Compressive Strength of the GPC vs GGBS/FA Ratio- 10 Molarity

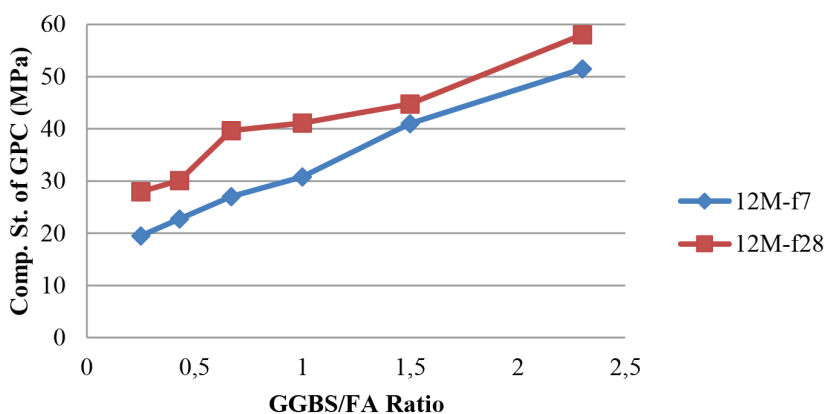

Fig. 1.4 Compressive Strength of the GPC vs GGBS/FA Ratio- 12 Molarity

Fig. 1 Compressive Strength of GPC vs GGBS/FA Ratio- For Different Molarities of Alkaline Activator

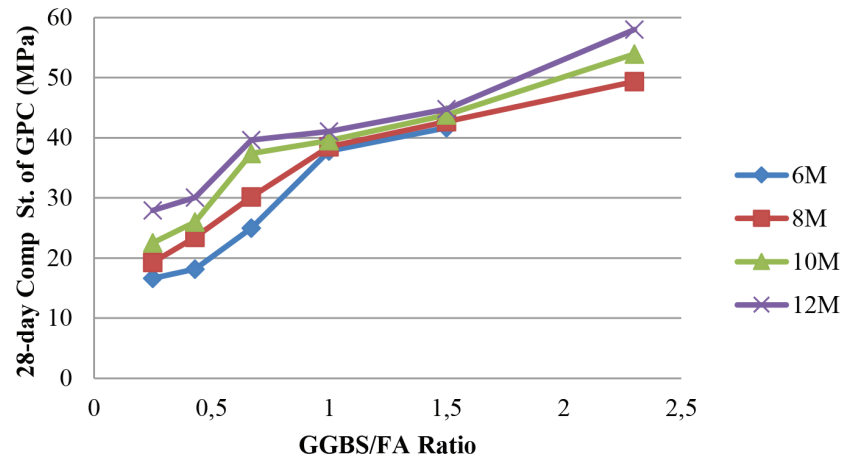

Fig. 2 28-day Compressive Strength of the GPC vs GGBS/FA RatioFor Different Molarities of Alkaline Activator

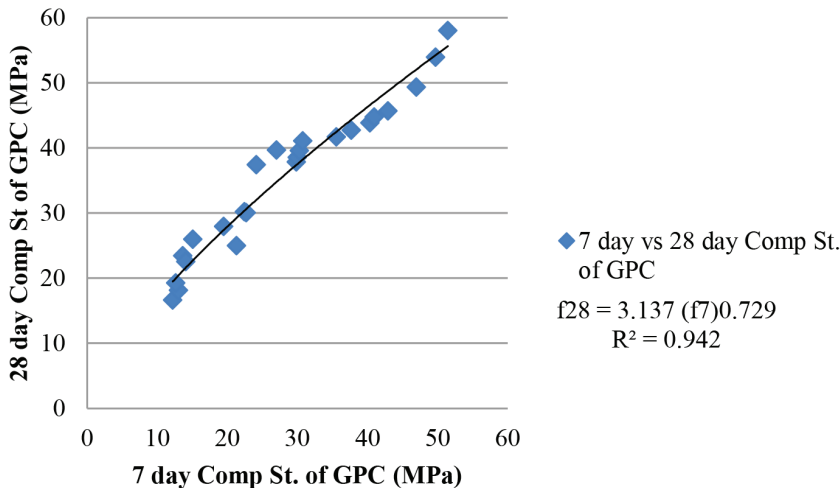

Fig. 4 Relation between 7-day to 28-day Compressive Strength of the GPC

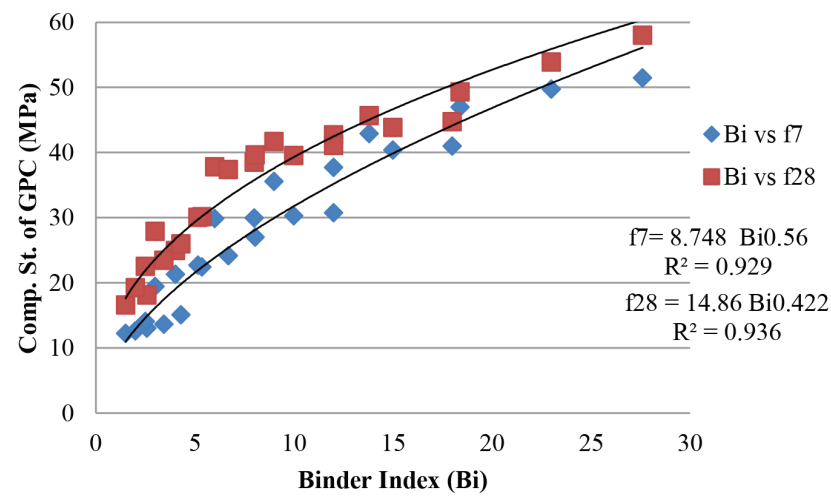

Fig. 6 Compressive strength of the GPC vs. Binder Index

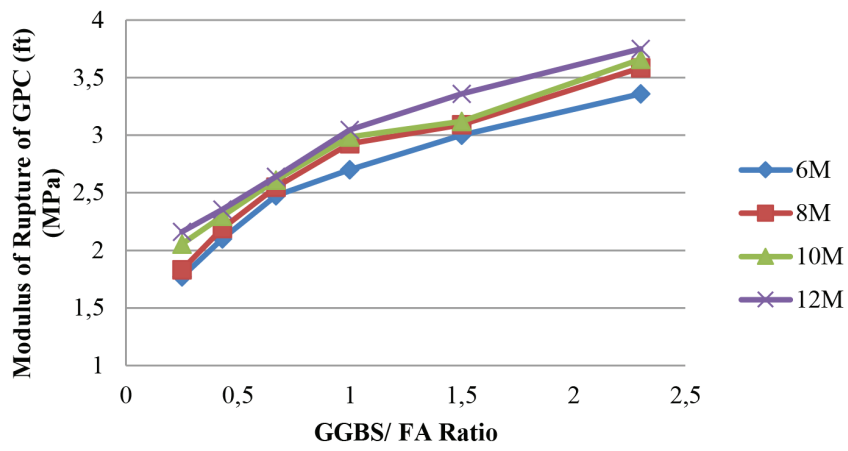

Fig. 3 Modulus of Rupture of the GPC vs GGBS/FA Ratio- For Different Molarities of Alkaline Activator

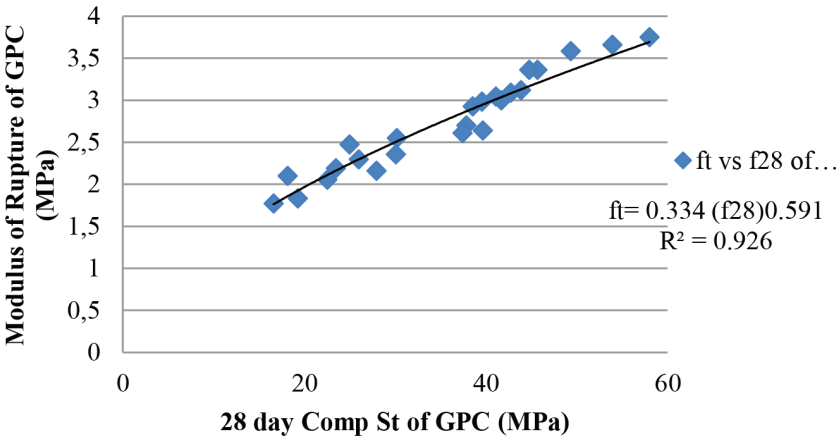

Fig. 7 Modulus of Rupture of the GPC vs. Binder Index

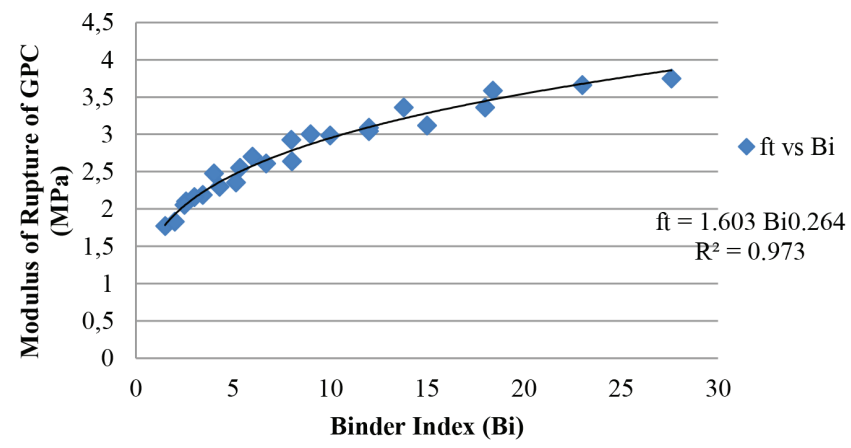

Fig. 7 Modulus of Rupture of the GPC vs. Binder Index 


\section{REFERENCES}

Anuradha R., Sreevidya V., Venkatasubramani R., Rangan B. V. (2012) Modified guidelines for geopolymer concrete mix design using Indian standard, Asian Jl. of Civil Eng., Build Hous, 13 (3), pp. 353-364.

Ashley Russell Kotwal, Yoo Jae Kim, Jiong Hu, Vedaraman Sriraman (2015) Characterization and early age physical properties of ambient cured geopolymer mortar based on class $C$ fly ash, International Journal of Concrete Structures and Materials, 9(1), pp. 35-43

Davidovits J. (1994) Geopolymers: Man-Made Geosynthesis and the Resulting development of Very Early High Strength Cement, J1. Materials Education, Vol. 16 (2\&3), pp. 91-139.

Hardjito D., Wallah S. E., Sumajouw D. M. J., Rangan B. V. (2004) On the development of fly ash-based geopolymer concrete, ACI Mater J., 101(6):467-72.

IS: 516-1956 (Reaffirmed 1999) Indian Standard Methods of Tests for Strength of Concrete.

Joshi R. K. (2014), Fly ash scenario in India, Scientist Report, Department of Science and Technology, India, pp. 1-18.
Lloyd N., Rangan B. V. (2009) Geopolymer Concrete-Sustainable Cementless Concrete, Gupta, R.Pawan and Holland, C.Terence and V.M. Malhotra, (ed), Tenth ACI International Conference on Recent Advances in Concrete Technology and Sustainability Issues, Oct. 12, 2009, pp. 33-53. Seville, Spain: American Concrete Institute.

Rajamane N. P., Jeyalakshmi R. (2014) Quantities of sodium hydroxide solids and water to prepare sodium hydroxide solution of given molarity for geopolymer concrete mixes, ICI Technical Paper, ICI Update - Aug. - Sep. 2014, pp. 4-8.

Rama Seshu D., Shankaraiah R., Sesha Srinivas B. (2017) Effect of GGBS to fly ash ratio and molarities of alkaline activator on the compressive strength of geo polymer concrete, J1 of CE\&CRAug , pp. 60-62.

Rangan B. V. (2008) Mix design and production of fly ash based geopolymer concrete, Indian Concrete J1, 82:7-15.

Wang S. D., Pu X. C., Scrivener K. L., Pratt P. L. (1995) Alkali-activated slag cement and concrete: a review of properties and problems, Adv Cement Res, 27:93-102. 